\title{
The Prevalence of Bovine Fasciolosis and Hydatidosis at Wolita Soddo Municipal Abattoir, Southern Ethiopia.
}

\author{
Firew Lejebo Leka" \\ National institute For Control and Eradication of Tsetse and Trypanosmiasis, Arba Minch, Ethiopia.
}

*Corresponding Author: Firew Lejebo Leka, National institute For Control and Eradication of Tsetse and Trypanosmiasis, Arba Minch, Ethiopia.

\begin{abstract}
A crossectional study was conducted from October 2007 to March 2008, at Wolita Soddo municipal abattoir, Southern Nation Nationalities and peoples regional state, where the prevalence of bovine fasciolosis and hydatidosis were assessed using antem mortem and post mortem inspection procedures. An overall infection prevalence rate of Bovine fasciolosis was 7.03\%(27/384), was recorded in examined cattle and an overall infection prevalence rate of Bovine Hydatidosis 11.46\%(44/384) was recorded in cattle. Among the fascilola species identified at soddo abattoir,74.1\% harbored Fasciola gigantica, $3.70 \%$ and $22.20 \%$ harbored Fasciola hepatica and mixed infection respectivelly. Out of total livers found positive for fluke infection, $70.4 \%$ were with bile duct distended and $29.6 \%$ were without distention of the bile duct. From total of organs found positive for hydatid cyst infection $18.18 \%$ were calcified and $81.82 \%$ were non calcified. On the other hand, from the total organs that were found positive for hydatid cyst infection, $65.9 \%$ occur in the lung and $31.82 \%$ and $2.27 \%$ in the livers, and both lung and liver respectivelly. During the study most of the slaughterd animals were originated from Wolaita zone(58.4\%) and the rest (41.6\%) were originated from neighbouring zones of Wolaita.This study demonstrated that Bovine fasciolosis and hydatidosis were prevalent in the area and causes great economic losses as a result of condomenation of infected organs, Lungs and livers.
\end{abstract}

Keywords: Bovine Fasciolosis, Bovine hydatidosis, prevalence, hydatidosis/echinococosis, Fasciola hepatica, Fasciola gigantica, Wolaita soddo

\section{INTRODUCTION}

Ethiopia, located in the horn of Africa between latitude from $3^{0} \mathrm{~N}$ to $15^{0} \mathrm{~N}$ of the equator and longitude from $33^{0} \mathrm{E}$ to $48^{0} \mathrm{E}$ (CSA,2003 and Tamire,2003) is an agrarian country with on estimated human population of about 62.9 million and total land of $1,101,000 \mathrm{~km}^{2}$ (Tamire,2003). The proportion of the total population in agricultural sector is $82.4 \%$ (CSA,2003). According to CSA (2003) and FAO.AGAL (2003) the livestock population of Ethiopia is about 30 million heads of cattle, 24 million sheep, 18millions goats, 7.2 million equines, one million camels, 25 thousand pigs and 55.6 million poultry.

Livestock are an important and integral part of farming system in Ethiopia. The livestock contribute about $18.8 \%$ of the total GDP for the country (FAO.AGAL,2003). Among livestock, cattle are the primary resource for the people and government of Ethiopia (ILRI,1999). However, the full exploitation of those resources is hindered due to combination of factors. Among these are the prevalence of numerous diseases particularly fasciolosis and public problem.

In southern nation nationalities and people`s state (SNNORS) region as in other part of the Ethiopia, the prevalence and occurrence of live stock disease is very high and they contribute much for the reduction of livestock production and productivity constraints. There are many diseases which have public and zoonotic importance (Minale, 2006). Among these are fasciolosis and hydatidosis.

Fasciolosis is disease of sheep, goat, cattle (Andrews, 1999) and occasionally result human infection (Okewole, et al.. 2000: WHO,1995). It is caused by genus Fasciola commonly called liver flukes, under the phylum plathyhelmnithes. The two most important species are fasciola hepatica, found in temperate and in cooler areas of high altitude in the tropics and subtropics, and fasciola gigantica which predominates in the tropical areas. The disease is characterized by weight loss, anemia and hupoproteinemia (Urquhart et al., 1996), Facscolosis, caused by Fasciola hepatica and Fascia gigantic, 
is one of the most prevalent helminth infection of ruminants in different part of the world causing significant morbidity and mortality (Okewole,et al., 2000: WHO, 1995).

Fasciolsis is considered as important limiting factors for bovine production. In general infection of domestic ruminants with Fasciola hepatica and Fasciola gigantica causes significant economic loss estimated at over US dollar of 200 million per annum to agricaultural sector worldwide with over 600milion animals infected (Ramajo,et al., 2001 ). In developed countries, the incidence of fasciola hepatica was reported up to 77\% spithill and delton (1998). Evidence suggests that sheep and cattle may be considered the main reservoir host species, pigs and donkeys being secondary. In tropical regions, fasciolosis is considered the single most important helminthes infection of cattle with prevalence rate of 30-90\% in Africa, 25-100\% in india and 25-90\% in Indonesia Spithill and Dalton (1998)

Generally considerable losses from liver condemnation and reduced meat production due to fasciolosis have been preported in different parts of Ethiopia (Yilma, 1984, Roman, 1987, Fekadu, 1988,Haymanot, 1990).Hydatidosis is and infection by metacestodes (larval hydatidcyst) or adult tape worm of the genus Echinococcus. It is cyclozoonosis with major economic and public health significant in many temperate and tropical areas (Moidrage and Ian, 1981) Hydatidosis/echinocccosis is azoonotic disease caused by the dog tape worm Ethinicoccus and its larval stage, the hudatid cust. This parasite is found world wide and causes serious public health problems in certain parts of the world (Schantz, 1990). In addition there are economic losses from the condemnations of affected organs. Echinoccosis is eyclozoonosis that requires two vertebrate hosts to uphold the life cycle (Schantz,1990) human con eccidanteny cecome intermediate hosts by ingesting the eggs of the tapeworm. While most cysts develop in the liver and lungs, other organs and tissue may become affected (Souls by, 1982) .

Hydatidosis is an important diseaseof ruminants in Ethiopia, affecting primarily the lung and liver. From public and economic point of view the cycle in dogs and domestic animals is more important. The adult parasite is small $(2-8 \mathrm{~mm})$ cestodes of carnivores especiallty dogs has anumber of strains. It is found in the small intestine of carnivores while metacestode (hydatid cyst) is found in different organs of wide variety of ungulates and man (souls by, 1982). Its larval stage, hydatid cyst, is disease of immense medical and economic importance (Smyth, 1985). Cysts usually grows $50-100 \mathrm{~mm}$, but size of up to $500 \mathrm{~mm}$ have been reported. The lesion increase in size whilst alive with budding off numerous daughter cysts and may attain on enomrmous size (Thompson and cotton,1985). The adult tapeworm is comparatively harmless to the dog though in large numbers enteritis may be seen (soulsby,1982). Although in herbivores the hydatid infection is not recognized as pathogenically or clinically important, there is no doubt, however, hydatdosis has an adverse effect on production causing decreased production of meat, milk, wool, reduced growth rate and predisposition to other diseases (Hubert,1985). Significant wconomic losses from liver and lung condemnation and carcass weight loss due to hydatidosis has been reported in different parts of Ethiopia (Yilma, 1984, Wubet, 1988, Alemayehu, 1990, Fikre, 1994, Bersissa, 1994).

In generally lung and liver represent the most commonly condemned organs due to Fasciolosis and Hydatidosis respectively. The nature and causation for fasciolosis and hydatidosis at area bases are not well studied. Especially the study of structural change of tissues and organs caused by different prevailing diseases are not recorded and become familiarized. Therefore the study of pathological lesions in bovines being slaughtered at this municipality abattoir is very important. The objective of the study is

- To determine the prevalence of fasciolosis and hydatidosis in bovines in the indicated abattoir

- To identify commonly involved species of fasciola.

- To identify gross pathological lesions in different organs of the slaughtered animal due to hydatid cyst and Fasciala.

- To investigate the origin of slaughtered animal to the indicated abattoir.

\section{LITERATURE REVIEW}

\subsection{Fasciolosis}

Fasciolosis is an important helminthes disease caused by two tremotodas fasciola hepatica \& fasciola gigantica (common liver fluke). The disease belongs to the plant borne trematode zoonosis the adult 
parasite F. bepatica has a leaf-like body, typical of flukes, and measures 20 to $30 \mathrm{~mm}$ long by 8 to 15 mm wide (dunn, 1978). It has an anterior elongation ( a cephalic cone) on which the oral and ventral suckers, which are approximately of equal size, are located. The intestine of the adult parasite is highly branched, with numerous diverticulae extending from the anterior to the posterior of the body. The pair of testes, also highly branched, is located in the posterior half of the body. The relative compact ovary is located just above the testes and is linked to a short convoluted uterus opening to a genital pore above the ventral sucker. The vitellaria are highly diffuse and branched in the lateral and posterior region of the body. F, gigantica is a parasite very similar to Fbepatica, its length may vary 25 to $75 \mathrm{~mm}$ long by $15 \mathrm{~mm}$ wide (Souls by, 1982). In addition, the cephalic cone is proportionally shorter than that of F, bepatica, and ids body even more leaf like in shape (Souls by, 1982). The egg of F. bepatica measures $150 \mathrm{pm}$ by $90 \mathrm{pm}$ in size and also very similar in shape to that of F.gigantica (Soulsby, 1982). The wgg of the latter is larger in size $(200 \mathrm{pm} \times 100 \mathrm{pm})($ Dunn, 1978). Fasciola eggs should be distinguished from the eggs of other flukes, especially from the large eggs of parampbistome. Fasciola eggs has a yellowish brown shell with an indistinct operculum and embryonic cells whereas parampbistome egg has transparent shell, distinct operculum with embryonic clear cells, and possess a small knob at their posterior end (Soulsby, 1982).

\subsubsection{Intermediate Hosts}

Snails of the genus Lymnaea are the intermediate hosts for genus Fasciola. The epidemiology of fasciolosis is dependent on the ecology of the snail intermediate hosts. Lymnaea species, most important in the transmission of F. hepatica, include: Lymnaea truncatula, widespread in Europe, Asia, Africa and North America; L. bulimoides in North America; L. tomentosa in Australia. Other species, which have been incriminated in the transmission of F. hepatica, include L. viator and L. diaphena ( South America), L. columnella (USA, Australia, central America and New Zealand) and L. humilis (North America) (Soulsby, 1982; Dunn, 1978),L. truncatula is the most common intermediate host for F. hepatica in different part of the world (Njau et. al., 1989) and in Ethiopia ( Graber, 1975). It is an amphibious or mud-dwelling snail which prefers moist temperature conditions (15-220C) though it appears that variants found in the tropics have adaptation to higher temperature mostly in the lowlands areas and can breed and survive at $26 \mathrm{C} 0$ with sufficient moisture. The most important intermediate hosts of F. gigantica are L. natalensis and L. auricularia (Urquhart, 1996; 1996; Dunn, 1978; Soulsby, 1982). L. natalenssis is the recognized intermediate host for F. gigantica (Yilma and Malone, 1198) Other species serving as secondarily hosts to this species are L.rufescens and L. acuminate (Indo-Pakistan) and L. rubiginosa (Malaysia). It serves as the intermediate host for F. gigantica (Urqhart, 1996) and requires well-oxtgenated non-polluted water bodies and can aestivate during dry periods, Optimal temperature requirement for the completion of parasite developmental stages within the snails is 22-26C0. However, in irrigated areas snail breeding is less circumscribed and will continue all year around. Except for perid`s extreme temperature levels.

\subsubsection{Life Cycle}

The life cycle of fasciola species. Is a typical of Digenetic treamatodes. Eggs laid by the adult parasite in the bile ducts of their hosts pass into the duodenum with the bile. The eggs then leave the host through the faeces. St this stage, eggs are still not embryonated, further development to maturation taking approximately two weeks. The eggs then hatch to release the motile miracidium, which will then locates and penetrates the intermediate snail host. The need to find a suitable host to penetrate is an urgent one, for those miracidia failing to do so generally die within 24 hours. After penetrating the snail, the miracidium loses its cilia and becomes a sporocyst. The sporocyst dividing and forming redia (forum with sucker and primitive gut), and a fully mature redia showing redia and cercariast stages.The cercaris of Fasciola species have a rounded body measuring between 0.25 and $0.35 \mathrm{~mm}$ long, with a long thin unbranched tail measuring approximately $0.5 \mathrm{~mm}$ long. The mobile cercaria snail generally leaves the snail 4-7 weeks after infection by migrating through the tissues of snails. This is during moist conditions when a critical temperature of $100 \mathrm{C}$ is exceeded. On emerging from the snail the cercaria attaches to submerged blades of grass or other vegetation like watercress; the tail falls away and the cercarial body secrates a four-layered cyst covering from cystogenous glands located on the lateral regions of the body. The formation of the cyst wall may take up to two days. The metacercartia (encysted, resisitant cercariae) is the infective form to the definitive host. Generally,metaceria are infective to ruminants such as cattle and sheep, but also to other mammals 
including human beings. One miracidium hateching from a fluke egg can produce up to 4,000 infective cysts (metacercarial) due to the vegetative multiplication at the sporocyst and redai stages.. The metacercarial syst is only moderately resistant, not being able to survive dry conditions. If however they are maintained in conditions of high humidity and cool temperatures, they may survive for up to a year (Andrews, 1999; Soulsby, 1982; Dunn, 1978).. The metacercarial cysts, when ingested along with the contaminated vegetation by the definitive host enter into the small intestine, releasing the young parasite which penetrates the gut wall, entering the peritoneal cavity. From there, it migrates directly to the liver over a period of approximately seven days, directly to the liver. The juvenile fluke (also referred to as adeloscaria) then penetrates the liver tissues, through which it migrates, feeding mainly on blood, for about six weeks. After this period, the fluke enters the bile ducts, maturing in to a fully adult parasite after about 3 months from initial infection. Egg production then commences and completing the life cycle (Fig.1)

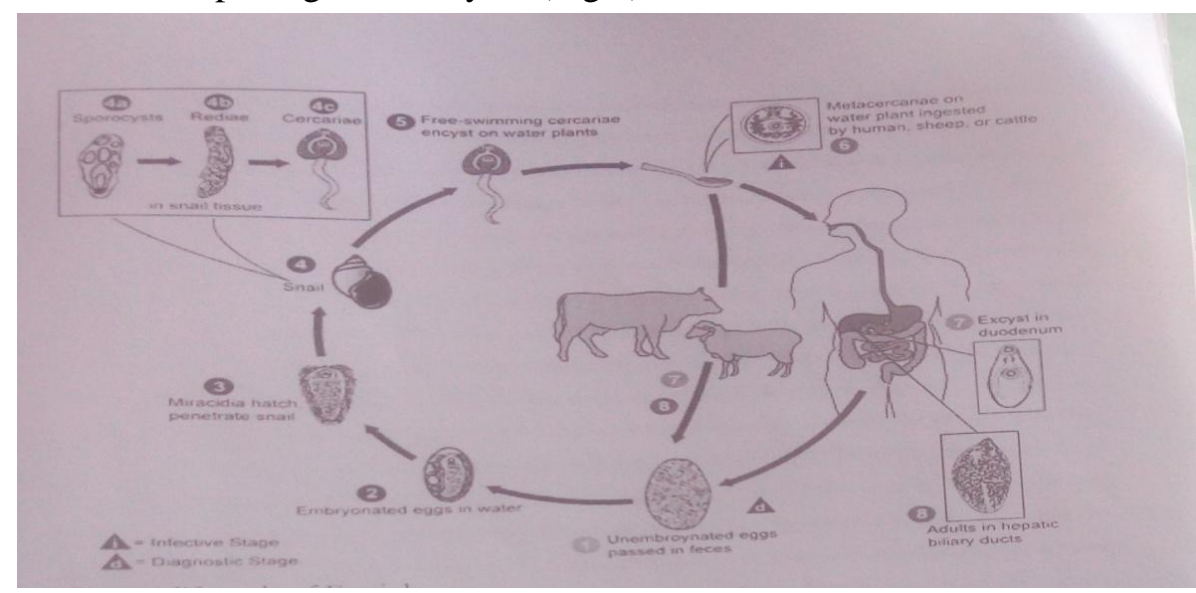

Figure1. Life cycle of Fasciola

Adult flukes can survive for many years in the livers of infected hosts and lay between 20,000 and 50,000 eggs/day. The rate of egg production is responsible for the degree of pasture contamination and thus greatly influences the epidemiology of the disease. The epidemiology of the disease is also influenced by the grazing habits of the animals. Animals grazing in wet marshy areas, favored by the intermediate host, are more likely to become infected. Typically, long and wet seasons are associated with a higher rate of infection. However, sheep are more likely to ingest large numbers of cysts during dry periods following a wet season. This is due a reduction in available pasture, forcing the animals to graze in swampy areas or in areas where the water has receded, thus exposing to vegetation heavily infected with metacercariae (Richter, et. al.. 1999). In the past, human fasciolosis was limited to populations within well-defined watershed boundaries; however, recent environmental changes and modifications in human behavior are defining new geographical limits and increasing the populations at risk (WHO, 1995).

\subsubsection{Pathology and Patho physiology}

Pathogenesis of fasciolosis varies according to the parasitic development phases: parenchymal and bilary phases. The parenchymal phase occurs during migration of flukes through the liver parenchyma and is associated with liver damage and hemorrhage. The biliary phase coincides with parasite residence in the bile ducts and results from the haematophagic activity of the adult flukes and from the damage to the bile duct mucosa by their cuticular spines (Urquhart, et, al., 1989). In the bile ducts of some permissive hosts, such as the sheep, rabbit, rat and mouse, the biliary stage of the disease is common. In others, such as cattle and humans, few flukes survive beyond the migratory phase and biliary is relatively rare (Behm and Sangster, 1999). Light infections due to Fasciola bepatica may be asymptomatic. However, they may produce hepatic colic with coughing and vomiting; generalized abdominal rigidity, headache and sweating, irregular fever, diarrhea and anemia (Behm and Sangster, 1999 ). In domestic ruminants, an adverse effect of acute or chronic fasciolosis includes decreased weigh gain and milk production, decreased female fertility, work power and mortality. Hepatic pathology, even when only limited areas of the liver are damaged, results in significant disturbances in mitochondrial bioenergetics metabolism of carbohydrates, proteins, lipids and steroids, as well as bile flow and bile composition (Calleja, et. al.,2000). Sheep and goat are very susceptible to acute 
fasciolosis and the damage results from the immature flukes tunneling through the liver parenchyma with extensive tissue damage and hemorrhage that culminate in severe clinical disease and high mortality in the grazing sheep in Africa (Okewleo,2000). During the movement of the immature stages of Fasciola bepatica, which may continue for months, symptoms may include abdominal pain, an enlarged live, fever, and diarrhea. Mitchell(2001) indicated that the pathology associated with diseases are caused by the inflammation of the bile ducts which causes thickening of the lining and eventually leads to fibrosis that results in reduced flow of the bile and back pressure builds leading to atrophy of the liver parenchyma and cirrhosis. Occasionally the worms penetrate the bile duct wall into the liver parenchyma causing liver abscesses. The complexity arises from several sources. Maturation of flukes involves development and growth for over 12-16 weeks during which time the fluke travels between and within organs. Because an individual fluke may pass the same part of the liver twice (or more) during these peregrinations, fresh and resolving lesions caused by the sequential insults may be found in the 12 same section of tissue; as the migratory fluke grows the size of its track through the liver increases as does the damage and the inflammatory response. Calves are susceptible to fasciolosis but in excess of 1000 metacetariae are usually required to cause clinical fasciolosis (Behm and Sangster,1999). The disease is characterized in calves by weight loss, anemia, and hypoprotenimia after infection with 10,000 metacercaria (Behm and Sangster, 1999). Resistance develop with age so that adult are quiet resistant to infection. Even though, the rate of development of human fasciolosis is similar to that in sheep, as an unnatural host, only few flukes develop suffisiently to reach the bile duct. Fasciolosis has a major effect of blood components (plasma proteins). Hypoalbuminanemia andhyperglobulinanemia commonly occur in liver fluke infections in all host species. During the parenchumal stage of the infection, liver damage caused by the migrating flukes compromise liver function, which in sheep and calves is reflected in a decline in plasma albumin concentrations, attributed partly to reduced rate of synthesis and partly to and expansion of the plasma volume (Behm and Sangster, 1999; Urquhare, et. Al., 1989). Nevertheless, during biliary stage of the infection loss of blood from haematophagia and into the intestines is so extensive, causing severe enaemia that sunthetic capacity of the liver in insufficient to replace the lost albumin ( small molecular size) that oozes through the huper plastic bile ducts (Chollengitis). Thus, a progressive loss of plasma albumin occurs in all infected host species, starting from around the time the fluke commences blood feeding. This results in disturbance in intravascular and extra vascular oncotic pressure leading to the development of edema, often markedly visible at submandibular region of ruminants (bottle jaw). Liver trauma is the abrasion caused by cuticular spines and the prehensile action of the suckers and appears to account for the majority of the damage caused in the liver. Death of the host is aconsequence of the hemorrhage induced by this damage. The oral sucker is the route by which liver flukes obtain most of their nutrition. It appears to cause considerable damage to liver tissue and macerated hepatic cells have been observed inside the sucker and pharynx. The oral sucker extends during migration and feeding from the curliest stages is capable of distupting cells. The muscular pharynx assists in this process and oral sucker is a major organ involved in tissue disrupting (Behm and Sangster, 1999). Although the inflammatory process has an important role in protecting the lost against severe.

Consequences of liver damage by the flukes, perthaps by retarding the growth of the parasite and contributing to hepatic healing process, there is accumulated evidence, in rats, that the response also contributes to hepatic dysfunction. There is evidence also that the infected rat liver is under oxidative stress during the parenchymal stage of the infection.

The liver plays a central role in the physiokogy of the body, being responsible for a large proportion of the body`s amino acid metabolism, for carbohydrate and liqid balance, urea synthesis, detoxification metabolism, ketogensis, albumin and glutathione sunthesis as well as aspects of homeostasis. Therefore, it is to be expecting that many systemic changes will be induced by liver fluke infections that ultimately cause reduced productivity in livestock. Both anorexia (inappetance) and the quality of the diet of infected sheep coffle contribute to hypoalbuminaemia during the infection (Behm and Sangster, 1999).

\subsubsection{Diagnosis}

Diagnosis of fasciolosis may consist of tentative and confirmatory procedures. A tentative diagnosis of fasciolosis may be established based on prior knowledge of the eqidemiology of the disease in a 
given environment; observations of clinical sigens, information on grazing history and seasonal occurrence. Confirmatory diagnosis, however, is based on demonstration of Fasciala eggs through standard examination of feces in the laboratory; postmortem examination of infected animals and demonstration of immature and mature flukes in the liver. The latter is helpful in deciding the intensity of infection. There are other laboratory tests (enzymatic and/ serological procedures used to qualify the infection mainly for research purposes. Serological assays are often used to detect infections due to immature forms where faecal egg output is often nil. Such tests allow the detection of substance like cathepsin L proteases, excretory secretary products of Ag in milk, and ELISA detection of antibodies against the flukes plasma concentration of Gamma-glutamyltransferase (GGT), which are increased within the duct damage.(Cornelissen, et. Al,. 2001; Soulsby, 1982; Urquhart et.el,. 1989) for example, Oxidative streass would be one of the consequsnces of the activity of inflammatory cells such as neutrophils, macrophages and eosinophils in producing oxygen-derived free radicals, nitric oxide and their products. A useful indicator of oxidative stress is the concentration of reduced glutathione (GSH) in cells. For chronic fasciolosis confirmatory diagnosis could casily carried out by coproscopic

Examination employing sedimentation technique. Fasciola eggs have high specific gravity and sedimentation is preferred to floatation. When the latter is employed, floating medium such as $\mathrm{ZnSo} 4$ should be used. As Fasciola eggs may be confused with parampbistomum eggs, addition of methylene blue in the faecal suspension will facilitate ease identification by providing a blue and contrasting microscopic field.

\subsubsection{Public Health}

Fasciolosis has recently been shown to be an important public health problem with human cases reported from countries in five continents, the level of endemcity ranging from hypo- to hyperendemic (Dela-Valero et, al., 2001). Human fasciolosis has also been reported in Europe, including Belgium, France, United Kingdom, Ireland, Swizerland and Spain (Ramajo, et al., 2001). The perception of human fasciolosis, caused by Fasciola bepatica or Fasciola gigantica, as an sporadic disease of low economic importance, is no longer tenable as the estimate of global prevalence is between 2.4 and 17 million human infections world-wide (Slifko, et. Al., 2000) and a further 180 million at risk of infection (Ramajo, et. Al., 2001). As a result, WHO (1995) has recognized fasciolosis as an emerging disease of humans. The distribution of the disease is predominantly rural, being associated with cattle and sheep breeding, although high prevalence in humans are not necessarily associated with area where fasciolosis is a significant veterinary problem. A few studies showed that the incidence appears to be concentrated within families, as they are all likely to consume the same contaminated product. The most common transmission route is the ingestion of watercress contaminated with encysted metacercariae, although, depending upon the geographical location, and a variety of edible aquatic plants can be vehicles of transmission. Water containing floating meatacercariae has also been implicated in disease transmission, as have salads contaminated with metacercaria-contaminated irrigation water. Among the risk factors are included the use of animal manure as fertilizers and wastewater effluent for irrigation aquatic or semi-aquatic vegetables (Slifko et. Al., 2000). High prevalence of human fasciolosis is recorded from peru and Bolivia.

\subsubsection{Control and Prevention}

Several control methods against ruminant fasciolosis are available and can either be used independently and as a combination of two or more of them. These methods involve reduction in the number of intermediate snail hosts by chemical or biological means, strategic application of anthelmintics, reduction in the number of snails by drainage, fencing and other management practices and reduction in the risk of infection by planned grazing management.

\section{Snail Control}

Control of parasitic diseases is crucial to improve the productivity of the animals. In most Fasciolosis endemic areas, the control of the intermediate snail host population offers a good Opportunity for the reduction of transmission and is generally effective when combined with one or more other methods such as chemotherapy or environmental sanitation. 
Although eradication of the snail hosts is the most effective method of total fluke controls this, however, is often very difficult in low-lying, wet areas with a mild climate. Snails multiply extremely rapidly and hence eradication is almost impossible in irrigation areas. There are different types ofsnail poisons available that are safe for stock but need care and precision in their application. Other useful methods of fluke control include biological control of the intermediate host, fencing the waterlogged area and so on (Hansen and Perry, 1994; Soulsby, 1982; Mitchell, 2001). The use of molluscicdes for the control of snail intermediate hosts is a potential tool for the control of fluke infections. Before considering chemical control of snails, it should be noted that many habitats are topographically unsuitable for the use of molluscicdes and it is often very difficult to apply them effectively. They are toxic to the environment, cooperation between neighboring properties is required for effective cover and regular (at least yearly) application is required because rapid repopulation of snails may occur. Whereas, they are not species-specific, may destroy edible snails highly valued as food in some communities and expensive (Hansen and Perry, 1994). A great number of chemicals have been used as molluscicides in the past, but at presentNiclosamide (Bayluscide or molloter) and copper sulfate are used in different part of African countries (Brown, 1980). Brown (1980) indicated that molluscicidal properties have been demonstrated in extracts from a variety of plants. A substance "Endod" or Lemma toxins derived from the fruits of shrubs Pbytolacca 16 dodecandra (Brown, 1980). Substance such as "Endod" might provide means of snail control less costly to developing countries then synthesized by molluscides but the production naturally molluscides on a commercial scale has yet to achieved. Tadesse and Getachew, (2002) from their finding they also indicated that 'Endod' used for the control of Fasciola transmitting snails particularly $\mathrm{L}$ truncatula and $\mathrm{L}$ natalensis.

\section{Chemotherapy}

Effective control of most trematode infections is based on strategically applied chemotherapy (Hansen and Perry, 1994). Combination of chemotherapy, intermediate host control, sanitation and environmental manipulation are believed to be more efficient but very expensive. A flukicidal drug of choice must fulfill the following

- It must act against both immature and mature flukes

- It must not be toxic to the recipient animal

- It must be cheap and easily available

Chemotherapy with drugs remains the most cost-effective way of treating parasitic diseases, and is usually at the heart of any major control campaign. Compared to environmental engineering, drug treatment is very cheap (Gaasenbeek, et. Al., 2001). The drugs to be used against flukes should ideally destroy the migrating immature flukes as well as adults in the bile ducts. Several drugs are now available for the treatment of fasciolosis, which are against the adult flukes, and theparenchymal stages. These include Rafoxanide, Nitroxynil, Brotanide, Closantel and Albendazole. Diamphentide kills all immature flukes even a day old once and the Triclbendazole (TCBZ) is highly effective against all stages of fluke. It is one of the widely used drugs worldwide for the control of fasciolosis (Spithill and Dalton, 1998; Gaasenbeek, et. Al., 2001).Chemotherapy normally reduces the prevalence and intensity of infection as measured by faecal egg counts (Hansen, et. Al., 1999).

\section{Environmental Sanitation and Manipulation}

Draining swamps, building sewage systems and providing clean water supplies are used to control water-borne /including snail borne/ helminthes but it is very expensive compare to chemotherapy (Hansen and perry, 1994; Gaasenbeek, et, al.,2001). Strategies for the treatment and prophylaxis of infections with Fasciola are developed based on eqidemiological data. Effective treatment during the prepatent period for an extended duration could eliminate Fasciola infection or reduce contamination of pasture to a very low level, requiring less frequent treatments for a considerable time ( Hansen and Perry, 1994; Yilma and Malone, 1998.Retardation of immature flukes, which survive treatment, appears to be applicable to all anthelmintics the degree of retardation depends on the efficacy of the drugs against the immature stages. This phenomenon has a great advantage in strategic control byreducing early pasture contamination with eggs. Less frequent strategic treatments with a possible yearly rotation of antelmintics or anthelmintic combinations that are effective against both immature 
and adult flukes has been reported to provide the best method of successful control of fasiolosis (parr and Fray, 2000). Other control control methods includes Rotational grazing (i.e. grazing animals in divided paddocke; grazing equines, then sheep etc) and also avoiding missed grazing of animals of different age groups (NB: Young animals are generally Susceptible to helminthes infections).

\subsection{Hydatidosis}

Hydatidosis (Echinococosis is an infection with adult tope worm or the larval hydrated cyst of the genus Echinococcus. The adult warm varies between $2-7 \mathrm{~mm}$ in length $\&$ usually possesses 3 or 4 segments ( rarely up to six (Solusby, 1982). The adult warm Echinococosis, in habits the small intestines of dogs, wolves, and coyotes, and the larvae, hydatid cysts, reside in the liver, lungs \& other organs of sheep, cattle, swine, horses, camel, wild ruminants, \& people (Jensen \& Swift, 1982).

Hydatidosis in livestock leads to considerable economic losses due to condemnation of edible offals primarily liver \& lung (Jensen and Swift, 1982). It is a public health \& economic problem of global proportions (FAO, 1982)

\subsubsection{Life Cycle}

The life cycle of Echinococcus granulosus involves two hosts \& a free living egg stage. Eggs are passed in the faeces of the carnivore, they are immediately infective and on ingestion by ungulates the oncosphere penetrates intestinal venule or lymphatic lacteal (Health, 1971) to reach the liver or lungs, although other organs can be infected ( Souls by, 1982). Accidental infection of man leads tometacestode development in liver, lungs or other organs (FAO, 1982). The hydatid cyst develops slowly over several months. Broad capsules, each containing protoscolices develop about is completed when a dog ingests protoscalices. Following ingestion, protoscolices repaginates, penetrate deeply between the villi into the crypts of lieberkuhn \& develop to maturity in about 47 days (souls by, 1982)

- Adult worm inhabit the small intestine of domestic dog and other canidae e.g. wolf, dingo, jackal

- Segments (proglottides) with eggs excreted in faces.

- Egg.

- Ungulates serve as intermediate hosts for hydatid cysts, which develop mainly in liver and lungs.

- Accidental infection of humans leads to development of hydatid cyst in liver, lung and other organs.

- Liver infected with hydatid cysts.

- Fertile hydatid cyst with protoscolices at the infective stage

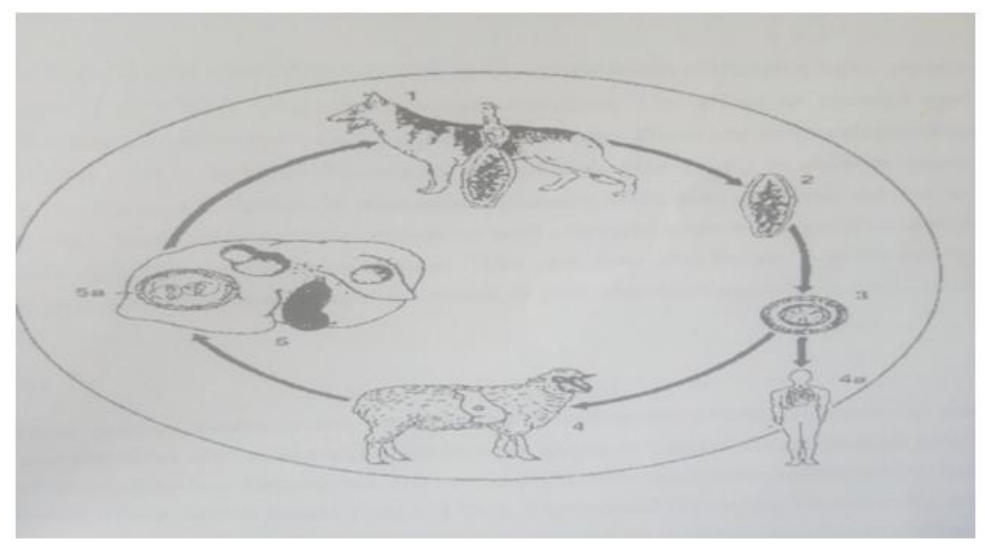

Figure2. Life cycles of echinococcus granulolosus

\subsubsection{Pathology}

The adult echinococcus is considered to be neither harmless to the definitive host, except when it occurs in large numbers, which may cause severe enteritis. The effect of hydatid cyst on the intermediate host depends on the size and location of the cyst. There are few available data on the 
clinical effects of the cystic hydatid disease in animal since the cyst is slow in growing and animal are often slaughtered before it manages to create sufficient pressure on the tissue or organs (Dunn, 1978). The hydatid cyst is normally well tolerated in humans until its development results in pressure on adjacent tissue or organs. The cyst may also bursts into the peritoneal or thoracic cavity, which can cause anaphylactic shock or give rise to many new cysts (Thompson \& Cotton, 1985).

\subsubsection{Diagnosis}

In the definitive host, a post-mortem examination is the most reliable method of diagnosis. Examination of the faces after using arecoline as a purgative is less reliable, although proglottides in the faeces are conclusive. Egg counts are not specific because of the similarity of eggs from other tapeworms of the Taenia family (FAO, 1982). Serological screening has recently proved to be a powerful tool in detecting infected dogs and is superior to the arecoline testing (Gasser etal, 1990).

In the intermediate host, diagnosing hydatidosis is possible through scanning, radiology, serology and postmortem examination. The post-mortem examination of sheep is usually an important component in monitoring the efficiency of control programmes (FAO, 1982).

\subsubsection{Public Health}

Human infection occurs because of contact with faecal contaminated material from infected canine hosts. The highest community prevalence of hydatid disease around the world is always in cattle or sheep herding populations with high levels of human-dog contact (Cox, 1986). The incidence at routine human autopsies varies greatly with the country. Among the highest figures is Greece, with 8.3 per 100,000, Cyprus with 12.9, Sardinia with 14.2, the Dalmatian. Province of Yugoslavia with 27.1 (though the country as a whole has only 3.7), Buenos Aires province of Argentina with 21.6 to 24.6 (the whole country having 3.14), and Uruguay with 20.7, Algeria with 5.1-6.1 (Angus, 1978; FAO, 1982). In East Africa infections in domestic livestock is widespread, dut infection in humans is mainly limited to certain groups in north western Kenys and Uganda, where a set of poorly understood environmental and cultural factors combine to produce one of the highest human morbidity rates yet reported (O`leary, 1976; Ower and Bitakarmire, 1975). Human behavior, such as, land tenure, attitude to doge socioeconomic factors, type of farming practices, where found to play a part in the epidemiology of transmission of hydatid disease (FAO, 1982)

\subsubsection{Control and Prevention}

Options for control include horizontal and vertical approaches. The former emphasis long-term primary health Care (education, sanitation, upgrading of meat inspection, etc.) with the aim to reduce disease transmission. However, this may not result in control of E. granulosus. The vertical approach is targeted to the parasite; it is based on specific control measure (dog population control, dog-dosing, etc.) and must include a base-line survey and surveillance of intermediate animal hosts to monitor progress (WHO, 1982)

\section{MATERIALS AND METHODS}

\subsection{Study Area}

\subsubsection{The Study Areas Location and Topography}

The study was conducted in southern nation nationalities and people`s regional state, Wolaita zone, at Soddo zuria woreda. Suddo zuria is one the twelve weredas of woloita zone and located at about $390 \mathrm{Km} 2$ southwest to Addis Ababa. The town Soddo is located at $8050^{`}$ Nand longitude $37045^{\circ} \mathrm{E}$. It has three different agro ecological zones high land (6.13\%), midland (81.7\%) and lowland (8.4\%) (WARDD, 2003).

\subsubsection{Climate}

Altitude ranges various from 110-2500 m.a.l The area experiences a mean annual temperature of about 190c, the highest average monthly temperature occurs in January when the mean maximum temperature is 26.20c and the coolest month is August when the average monthly minimum temperature is about $11.40 \mathrm{c}$. The rainfall region over much of the area is typically bimodal with the big rainy session extending from June to September. And a small rainy session occurring from February to April. The mean annual rainfall of the area ranges from, 180-1446mm with the lowest 
being in the lowlands and the highest in the highland (Soddo metrological station record) (Demelash et al,2005).

\subsubsection{Agricultural System and Livestock Population}

The prevsailing agricultural system in the region is mixed farming with crop and livestock production the subsistence needs of rising human population are resulting in the progressive extension of the area under cultivation and subsequest limitation of grazing lands. The livestock population in Soddo zuire is estimated to be 94,006 cattle 11,384 sheep 3,164 goats and 429 horses, 5000 mules, 4,020 donkeys and 55,191 chickens (WZFED, 2004).

\subsection{Study Animals}

The study animals comprised indigenous local cattle, which are slaughtered at Suddo municipal Abattoir. Most of the slaughtered animals (58.4\%) were originated from the wolotia zone (Humbo, Areka, Bale, Bodittle, Suddo zuria, Abella and Badessa) and the rest 41.6\% (Boroda, mirababaya, wake, Goffa and Arbaminch). Great emphasis was given to factors such as body condition and origin of the animal to determine the impact of those factors on the occurrence of the disease. However, almost all cattle presented for slaughter were local breed, males and adult in age

\subsection{Study Design}

A cross sectional study type was conducted to determine the prevalence rate of bovine fasciolosis and hydatidosis by using postmortem examination of different organs. During the study special attention was given to lung, liver, heart, kidncy and spleen of each slaughtered animals and were carefully examined by visualization and palpation, of the entire organ that was followed by incision of the organ in order to confirm the case (Urquhart, 1996, Soulsby, 1982).

\subsection{Data Collections}

Appropriate data were collected by using postmortem examination of the organs which are affected by the disease. An interview was made with cattle owner in the cattle market and butchers in the slaughter house regarding the origin of slaughter animal. Based on the interview most of the slaughter animals were from the zone itself and the rest were brought from the surrounding zone.

\subsection{Sample Size and Sampling Method}

The total number of cattle that were examined or inspected in this study was calculated using the formula given by Thrusfield (1995) taking 50\% prevalence and CI level of 95\%. It was calculated

$$
n=\frac{z^{2} P(1-p)}{d^{2}}
$$

where;

$\mathrm{n}=$ sample size required

$\mathrm{z}=$ taken from table for the $95 \%$ CI (1.96)

$\mathrm{p}=50 \%$

$\mathrm{d}=$ level of precision

$\mathrm{n}=(1.96) 2(0.50)(1-0,10)$

$(0.05) 2$

$\mathrm{n}=384$

\subsection{Study Methodology}

\subsubsection{Ante Mortem Examination}

The animals were visited for ante mortem inspection with maximum of three days used and a minimum of two day perweek forassessment of origin of the animal and general health status of the animal. During each visit the animals were identified based on the number written on the body of the animal and the general physical examinations of the animal were conducted. 
The Prevalence of Bovine Fasciolosis and Hydatidosis at Wolita Soddo Municipal Abattoir, Southern Ethiopia.

\subsubsection{Post mortem Examination}

After having although visual inspection, palpation, systematic incision of each liver, lungs, heart, spleen and kidney were made (soulsby, 1982). All livers and lungs condemned due to flukes and hydatidosis respectively were registered and the liver were collected for species identification and the gross lesions of the organs were observed and registered during the examination.

\subsubsection{Species Identification}

After making systematic incision on the bile duct and liver parenchyma, flukes were collected in universal bottles and then examined to identify the involved species, species identification was conducted based on souls by (1982).

\subsubsection{Prevalence Study}

From October 2007 to March 2008 liver and lung from 384 local cattle breeds were examined following post mortem meat inspection procedure. All livers and lung condemned due to fasciolosis and hydatidosis were collected and used for flukes and cyst prevalence study in addition to these the lesion produced due to the parasite were recorded for the further study on the gross lesion.

\subsubsection{Gross Lesion Identification}

The lesion produced due to fascuiolosis and hydatidosis were observed during the examination and the condition of the organ due to huydatid cyst and fasciola were registered including the bile duct condition and nature of the cyst.

\subsection{Data Analysis}

The collected date were entered in to excel and described by using descriptive statistic and expressed by using tables and graphs.

During this time using purposive sampling method in which each animal that slaughtered in the slaughter house were examined

\section{RESUlT AND Discussion}

\subsection{Result}

\subsubsection{Fasciolosis}

\section{Prevalence}

A total of 384 adult indigenous cattle slaughtered at Wolaita Soddo abattoir were examined for fasciolosis and hydatidosis. Of the total cattle examined $7.03 \%(\mathrm{~N}=384, \mathrm{n}=27)$ of them were found to be positive for fasciolosis as shown on table1.

Table1. Showing prevalence of bovine fasciolosis at soddo abattoir

\begin{tabular}{|c|c|c|}
\hline Number of animal examined & \multicolumn{2}{|c|}{ Fasciolosis } \\
\hline \multirow{2}{*}{} & Positive\% & Negative\% \\
\cline { 2 - 3 } & 7.03 & 93 \\
\hline
\end{tabular}

\section{Fasciola Species Identified}

From a total of 27 cattle that were positive for liver fluke infection during postmortem inspection $74.1 \% 0$ of them harbored f.gigantica, 3.70\% F.hepatica and $22.2 \%$ mixed infection

Table2. Proportion of Fasciola species identified at Suddo Abattoir

\begin{tabular}{|c|c|c|c|}
\hline \multirow{2}{*}{$\begin{array}{c}\text { Percentage of total } \\
\text { positive }\end{array}$} & \multicolumn{3}{|c|}{ Percentage of species identified $(\mathrm{N}=384)$} \\
\cline { 2 - 4 }$(\mathrm{N}=384, \mathrm{n}=27) 7.03 \%$ & Fasciolagigantica(n=27) & Fasciolagigantica(n=27) & Mixed(n=27) \\
\cline { 2 - 4 } & 74.1 & 3.70 & 22.2 \\
\hline
\end{tabular}

\section{Identified Lesions with Respect to Bile Duct Condition}

From a total of 27 livers that were found positive for liver fluke infection during postmortem inspection 19(70.4\%) and 8(29.6\%) cattle`s were with bile duct distended and without distension of bile duct respectively. 
The Prevalence of Bovine Fasciolosis and Hydatidosis at Wolita Soddo Municipal Abattoir, Southern Ethiopia.

Table3. The condition of liver during postmortem inspection.

\begin{tabular}{|c|c|c|c|}
\hline $\begin{array}{c}\text { Number of animal } \\
\text { examined }\end{array}$ & $\begin{array}{c}\text { Number of } \\
\text { animal positive }\end{array}$ & \multicolumn{2}{|c|}{ Lesion with respect to bile duct condition } \\
\hline 384 & $27(7 \%)$ & With distended bile duct & Without bile duct distension \\
\cline { 2 - 4 } & & $19(70.4)$ & $8(29.6)$ \\
\hline
\end{tabular}

\subsubsection{Hydatidosis}

\section{Prevalence}

Out of 384 cattle slaughtered and examined at Soddo municipality abattoir 44(11.46\%) of them were found positive for hydatidosis.

Table4. Prevalence of bovine hydatidosis at Soddo municipality abattoir from October to March 2007/2008

\begin{tabular}{|c|c|c|}
\hline Number of animal examined & \multicolumn{2}{|c|}{ hydatidosis } \\
\hline \multirow{2}{*}{384} & Positive percentage & Negative percentage \\
\cline { 2 - 3 } & 11.46 & 88.54 \\
\hline
\end{tabular}

\section{Rate of Infection of Various Organs}

The rate of occurrence of hydatidosis in various visceral organs during the study period is indicated in figure. 3

Figure.3 rate of infestation of various organs of cattle slaughtered at Soddo municipal abattoir with Hydatid cyst.

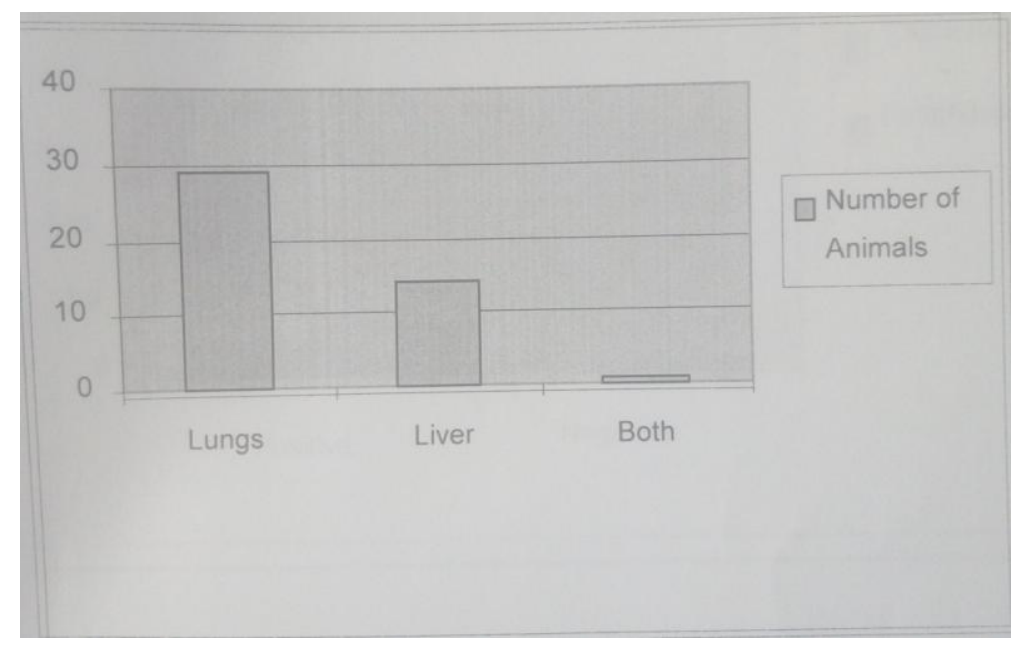

Figure3. Frequency of Hydatide cyst occurrence in various organs at soddo abattoir

\subsubsection{Hydatidosis and Fasciolosis}

From a total of 384 animals examined both for hudatidosis and fasiolosis, totally $18.5 \%$ cattle $(\mathrm{N}=384$ and $n=7)$ were affected by hydatid cyst and fasciola, $7.03 \%(\mathrm{~N}=384, \mathrm{n}=27)$ by fasciolosis and $11.46 \%$ $(\mathrm{N}=384, \mathrm{n}=44)$ by hydatid cyst.

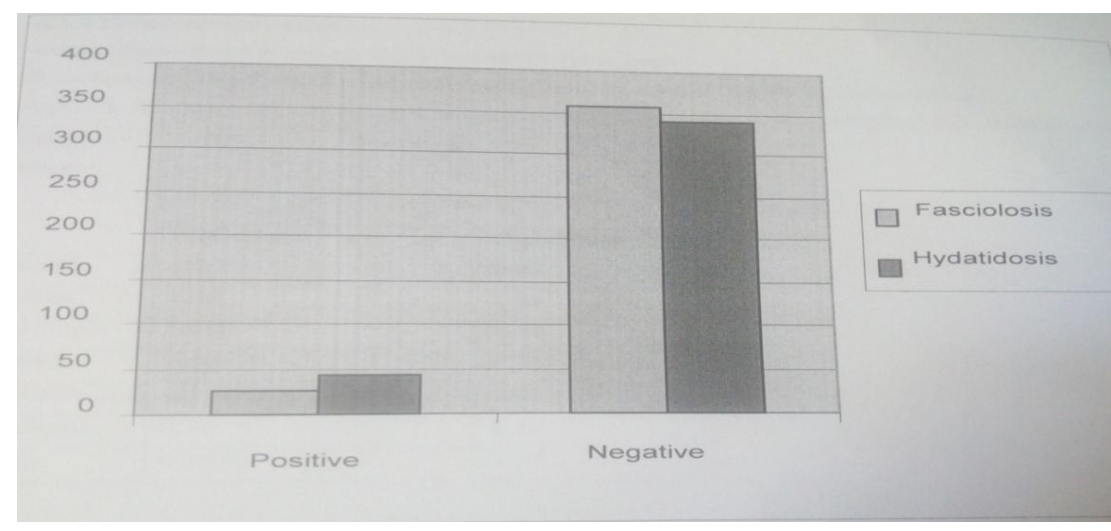

Figure4. Comparisons of fasciolosis and hydatiosis at wolaita soddo abattoir 
The Prevalence of Bovine Fasciolosis and Hydatidosis at Wolita Soddo Municipal Abattoir, Southern Ethiopia.

\subsubsection{Origin Identification}

\section{Prevalence Based on Origin within Wolaita Zone}

Prevalence of Fasciolosis and hydatidosis based on origin within in wolaita zone

Table5. Showing prevalence of fasciolosis and hydatidosis based on origin within wolaita zone

\begin{tabular}{|c|c|c|}
\hline \multirow{2}{*}{ Origin place } & \multicolumn{2}{|c|}{ Prevalence (\%) } \\
\cline { 2 - 3 } & Fasciolosis & Hydatidosis \\
\hline Humbo & 1.30 & 2.08 \\
\hline Areka & 1.04 & 1.26 \\
\hline Boditte & 0.26 & 0.78 \\
\hline Abella & 0.52 & 0.26 \\
\hline Soddozuria & 0.26 & 0.52 \\
\hline Badessa & 0.26 & 0.52 \\
\hline Bale & 0.25 & 2.34 \\
\hline
\end{tabular}

\section{Prevalence Based on Origin Outside Wolaita Zone}

Table6. Showing prevalence of Fasciolosis and Hydatidosis based on origin outside wolaita zone.

\begin{tabular}{|c|c|c|}
\hline \multicolumn{2}{|c|}{ Prevalence (\%) } \\
\hline Origin place & Fasciolosis & Hydatidosis \\
\hline Boroda & 1.82 & 0.78 \\
\hline Mirab abaya & 0.78 & 0.52 \\
\hline Arbaminch & 0.26 & 0.52 \\
\hline Goffa & 0 & 0.78 \\
\hline Waka & 0 & 0.78 \\
\hline
\end{tabular}

\subsection{Discussion}

This study revealed that hydatidosis and fasciolosis are highly prevalent and stand first among parasites causing considerable direct and indirect economic losses in the study area. Bothe parasites are primarily responsible for condemnation of edible organs such as livers \& lungs causing significant economic losses.

In this study the prevalence rate of fasiolosis was 7.03 , its prevalence economic significant has been reported by different works. Different studies carried out on the importance of fasciolosis in different part of Ethiopia showed the enormous economic impact of the diseases mainly due to liver condemnation \& losses of livestock production Graber (1975), Bahru \& Ephreme (1979) indicated the existence fasciolosis in almost all regions of Ethiopia

In the present study the prevalence rate of fasiolosis was $7.03 \%$ recorded which is lower when compared with previous reports in different parts of the country as Daniel (1995) at Diredawa (14.4\%) Dagne (1985) in Debre Birhane (88.6\%) Bahiru \& Ephereme (1979) in keffa (86\%) Fekadu (1988) in Bahiredar (84.7\%), Zewdu (1991) in Jimma (47.45\%), Abdul (1992) in Soddo(47\%) Yohjannese (1994) in BahirDar (16.97\%) and Mogos (2003) in Jimma (57.53\%) this might be due to difference in climate unfavorable agro-ecology for the development of intermediate host or availability of suitable snail habitat (Uquhart et al, 1996), optimal base temperature to levels of 100c and 160c are necessary for snail vectors of fasciola hepatica and fasciola gigantica respectively. The difference in prevalence and severity of the diseases sundrome are evident in various geographical regions on the local climatic condition, availability of permanent water and system of management (Lossos, 1986). From the total livers, $74.1 \%$ of them were found to be positive for fascilosis infected by fasciola gigantica where as Fasciola hepatica and mixed farms were recovered to be $3.70 \%$ and $22.2 \%$ respectively.

It this study the predominant species causing fasciolosis was faciola gigantica. This finding is in agreement with Takele (1995) who indicated fasciola gigntica as the predominat species. This finding is also due to the origin of slaughter animal from low land area of wolaita zone. This is in agreement with Graber (1975) who indicated that fasciola gigantica appears to be most common species in area below 1200 \& between 1200 to 1800 as mixed infection. In this study, the prevalence rate of hydatdosis was 11.46, this finding is inline with that of Daniel (1995), who reported $13.7 \%$ prevalence of Boving hydatidosis at Diredawa abattoir, but is is relatively higher that the prevalence $7.2 \%$ reported by Tsegaye (1995) from Debre Bithane abattoir. 
Higher prevalence of bovine hydatidosis were recorded in other regions of Ethiopia which include Wubet (1988) in Bale Robe (62.96). Nebiyou (1990) in Bahirdar (54.9\%). Alemayehu (1990) in Asella (54.8\%), Yilma(184) in Debre Zeit (46.5\%), Fekadu (1997) in Asella (72.49\%) This difference in the rate of occurrence of hydatiosis in various parts of the country, Ethiopia is probably due to the following reasons. The difference in social factors primarily in keeping dogs \& feeding infected offal's, such dogs contaminate, pasture with theirfaces containing echinococcus eggs. The custom of stray dogs elimination, the practice of backyard slaughtering by the community. The hygienic condition of the abattoir in the specific area. Dogs and cultures access to infected offal's or organs.

The rate of occurrence of hydtidosis in various in various organs is shown on figure3.

It reveals that the lung (65.9\%) is affected more frequently that liver. This finding is in general agreement with the finding of Arena (1985), Roman (1987), Getachew (1991), Dessie (1992),Mohammed (1988), Abduljewd (1988). The higher degree of infection of lungs is attributed to the increased diameter of capillaries (William et al, 1975 \& Grecey, 1986). Out of the total cyst examined and relatively high percentage $(81.82 \%)$ werenon calcified and the rest $(18.18 \%)$ were calfled. Higher percentage proportion of calcified cyst occur in liver (75\%) compared with lung (25\%) which probably could be attributed to higher reticuloendothelial and connective tissue reaction of the organ.

\section{CONCLUSION AND RECOMMENDATION}

This study demonstrated that bovine fasciolosis and hudatidosis ration were prevalent in the area and causes great economic losses as arsult of condemnation of infected organs, liver and lung the study showed that there is high prevalence of hydatidosis (echinococcosis) that followed by fasciolosis. The high prevalence of hydatidosis is mainly due to feeding of dog with infected internal organs, with cysts, dogs (definitive host ) in turn shed eggs of this tape warm with their faces and contaminate the environment (postures, drinking water sources, vegetable etc) and intermediate hosts (sheep, goat, cattle \& even man contract the infection from contaminated environment.

The prevalence of fasciolosis is not simple. The dominant species of fasciola observed was gigantica which is associated with the origin of slaughter animal from low land area but the two major species of fasciola ( Fasciola hepatica and Fasciola gigantica) were identified indicating the current availability of favorable climatic condition in the study area for the development of intermediate host. The low prevalence of fasciolosis was due to long dry season which created an unfavorable condition for the development 0 of snail intermediate host.

Based on the above conclusion the following recommendations are forwarded:

- Detailed epidemiological studies on the prevalence of both fasciolosis and echinococcosis should be conducted taking in to consideration agro ecological situation of the regional state.

- Destruction of pathological materials (destruction of dog faces and infected internal organs from secondary hosts).

- Collection of statistical data on dogs \& other animal population is important in preparing strategies \& launching campaigns for the control.

- Backyard slaughtering of animals should be prohibited through designing and reinforcing of legislations, construction of slaughter houses with fulfill the necessary, and implementation of proper meat inspection services.

- Strategic use of flukocidal drugs based on adequate eqidemiological information`s seems the most probable method in the control of the fasciolosis.

- Biology of intermediate host (snail) should be conducted \& appropriate habitats of the intermediate host should be identified

- The development of intensive farming techniques has proved to be associated with the decrease \& even eradication of the diseases.

- Public awareness of health risks connected with fasciolosis and hydatidosis can greatly assist in reducing the spread of diseases. 
The Prevalence of Bovine Fasciolosis and Hydatidosis at Wolita Soddo Municipal Abattoir, Southern Ethiopia.

- People have to be well oriented about proper pet feeding (they should avoid feeding dogs raw meat and offal and meat product before feeding to dogs)

- There should be extended abattoir/slaughtered slab services at rural areas

\section{REFERENCE}

[1] Abdul,s.(1992):Economic significance of bovine fasciolosis and hydatidosis at soddo Abattoir, DVM THESIS, FVM,AAU, Debrezeit, Ethiopia, pp127.

[2] Abduljewad,A.(1988):Hydatidosis prevalence at Jimma abattoir DVM THESIS, FVM,AAU, Debrezeit,Ethiopia, pp55

[3] Alemayehu,H,(1990), The prevalence of hydatidosis in cattle, sheep,goat \& echino Coccus granulosus in dogs in, Arsi administrative region, Dvm thesis, Addis ababa University, faculty of veterinary medicine, Debrezeit, Ethiopia pp 26

[4] Andrews,S.j.(199).The life Cycle of Fasciola bepatica. In: Fasciolosis (Dalton,J.P.ed).CABI publishing, Walling ford,UK.pp. 1-30.

[5] Angus, M.D (1978) Veterinary helminthology. $2^{\text {nd }}$ edition, London, Willian heinmanMedical Books LTDpp322.

[6] Arene,F.O.I(1985): Prevalence of hydatid cysts on domestic livestock in the Niger Delta. Tropical animal health \& production, 17(1):3-5

[7] Bahiru,G\& Ephrem, M.(1979): APreliminary survey of bovine fasciolosis. Ethiopia. Journal of Agricultural Science 1 (1): pp 5-12

[8] Behm, C,A. sangster, N.N.(1999). Pathology, path physiology and clinical aspects. In Easciolosis (Dalton,J.Ed)CAVI publishing, walling ford,UK pp. 185-224

[9] Bersissa,K.,(1994) Hydatidosis in Nekemte: prevalence in slaughtered cattle and sheep, Estimated economic loss \& incidence in stray a dogs, DVM thesis, Addis Ababa University, faculty of veterinary medicine, Debre Zeit, Ethiopia, pp,40

[10] Brown, D,S. (1980). Fresh water snails of Africa and their importance. Taylorand Frands. LID.london, pp487.953-958.

[11] Calleja, C, Bigot, K, Eeckhoutte, C, Sibille, P, Boulard, C. and Galtier, P, (2000). Comparison Of hepatic and renal drug-metabolizing enzyme activities in sheep given Single or two-fold challenge infections with fascioloa bepatica international journal for parasitology $30(8): 65$

[12] Cornelissen, B.W.J., Gaasenbeek, P.H, Borgsteede, H.H, Holland, W. G. Harmsen, M. M and Boersma, W. J. (2001). Early immune diagnosis of fasciolosis in ruminants Using Rrecombinat Fasciola bepatica cathepsin L like protease. International Journal for Parasitologh 31(7): 728-737

[13] Cox, F,E.G (1996): Modern parasitology $2^{\text {nd }}$ edition, black well science, LIT, Great Britain. PP276

[14] CSA (2003) Ethiopia agricultural sample enumeration results for SNNPR statistical report on Livestock \& form implements, port, and IV pp.29-304

[15] Dagne, M (1994): Survey on prevalence and economic significance of Boving fasciolosis in Debre Birhane region, DVM THESIS, FVM, AAU, debrezeit, Ethiopia,pp174

[16] Daniel. F(1995): Economic importance of organ condemnation due to fasciolosis and Hydatidosis in cattle and sheep slaughtered at diredawa abattoir. DVM thesis, FVM, AAU, debrezeit, ethiopiapp196-197.

[17] Demelash, B, Etana, D, and Fekadu B. (2005): Prevalence and risk factors of mastitis in Lactating dairy cows in southern Ethiopia, international Journal for applied Research of veterinary medicine, 3:189-198

[18] Dessie Sheferaw (1992): Economic significance of bovine hydatidosis,fasciolosis \&Cysticercosis of asela abattoir, DVM thesis, Addis Ababa University, Faculty of veterinary medicine.

[19] Dunn, S. (1978) veterinary helmnthology. Great Britain.

[20] Dela-Valero M.A,Darce, A.N.,Panova, M. and Mas-Coma, S. (2001). Relationships Between host species and morphometric patterns in Fasciola bepatica adults and Eggs from the northern Bolivian Altiplano Hyper endemic region. Veterinary Parasitology 102 (1-2): 85-100.

[21] FAO (1982):Echinococcus (hydatidosis; surveillance, prevalence and control FAO/UNEP/WHO guidelines, FAO animal production and health paper No.29.Rome.

[22] FAO(UNEP) WHO (1982): guide lines for echinococcosis/hydatidosis ( surveillance, Prevention and control FAO, Rome, No.29,pp.147

[23] FAO, AGAL (2003) Livestock sector brief, Ethiopia

[24] Fekadu Olike (1997): Study on prevalence and economic significance of hydatidosis in Ruminants 
The Prevalence of Bovine Fasciolosis and Hydatidosis at Wolita Soddo Municipal Abattoir, Southern Ethiopia.

echinococcusgranulosisindogsinandaroundasella. DVM THESIS, FVM,AAU, debrezeit, Ethiopia, PP243244

[25] Fekadu.R(1988); Apreliminary survey on bovine fasciolosis around Bahir Dar and Evaluation Of flukocidial activity of rafoxinideand cloxantel preparation. DVM THESIS,AAU,FVM, debrezeit, ETHIOPIA, PP24

[26] Fikre, L, (1994): Echinoccosis/hydatidosis in konso, Southern Ethiopia. An assessment Trail of its Prevalence, economic \& public health importance, DVM thesis,AAU, FVM, Debre Zeit, Ethiopia pp41

[27] Gaasenbeek, C.P.H.Moll, L, Cornelissen, J.B.W.J,Vellema,P. and Borgsteede, F.H.M.(2001) . An experimental study on Triclabendazole resistance of Fasciola bepatica in Sheep, Veterinary Parasitology 95 (1):37-43.

[28] Gasser, R.B.lighowlers,M.w.Richard,M.D. and Dawkins, H.J(1990). Serological Screeining of farm dogs for echinococcus granulasus infection in an endemic region.ausrtalian veterinary journal

[29] Getachew Jember (1991): prevalence of hydatdosis in cattle of awassa abattoir. DVM thesis, Addis Abeba, University faculty of ceterinary medicine, Debrezeit,Ethiopia.

[30] Grabber, M. (1975). Helminthes and helmenthiasis of domestic and wild animals in Ethiopia. Bulletin of animal health and production in Africa, 23:57-86.

[31] Graber, M.(1978).main helminthes \& helminthiasis in Ethiopia. Vol.I, pp183-186

[32] Gracey,J.F (1986) meat hygiene, $8^{\text {th }}$ Edition, Bailliere Tindal publisher, London.

[33] Hansen, J and Perry, B. (1994).The Eqidemiology, diagnosis, control of helminth Parasites of ruminants: A Handbook. Animal production \& health diversion, FAO, Rome, Italy PP, 171

[34] Hansen,D.S.,Clery,D.G.,Estuningsih,S.E.Widjajanti,S.,Partoutomo,S.andSpithill,T.W.(1999). Immune response in Indonesian thin tail and Merino sheep during a Primary infection with Fasciola gigantica. Lack of a specific IgG2antibody response is Associated with increasedresistance to infection in Indonesian sheep. International Journal for Parasitology 29(7): 1027-1035.

[35] Haymanot, A. (1990): Prevalcnce \& bovine survey of bovine fasciolosis in eastern Haregie DVM thesis, Faculty of Veterinary Medicine, Addis Ababa University, Debire Zeit, Ethiopia, pp. 21

[36] Health,D,D.(1974), The migration of conchospheres of T. pisformis, T. sinlasis and Echinococcus granulosus, with in the intermediate host, international J, paraditol, 1:145-1652

[37] Hubert, W, T. ET AL, (1985): Disease transmitted from animals to man $6^{\text {th }}$ edition chorler. C. Thomas publisher., Illinosis U.S.A,pp,686-692

[38] IIRI (1999),Making the livestock revolution work poor, annual report, ILRI, Nairobi Kenya, pp1-32

[39] Jensen \& Swift, B.L (1982): Disease of sheep. $2^{\text {nd }}$ Ed, U.S.A Philadelphia lea \& Febiger pp.330

[40] Lossos, G. J (1986): Infections, Tropical disease of Domestic Animals. International Center in black Africa in Rev.med.vet.Pays. Trop. 37:299-303

[41] Minale (2006): Report on gross pathological lesions in selected regions of Southern Nation Nationalities \& Peoples Regional state, unpublished.

[42] Mogos, .E. (2003) Study on bovine fasciolosis and hydatidosis at jimma municipal Abattoir. DVM THESIS FVM, AAU, DEBREZEIT, ETHIOPIA.Pp15-19.

[43] Mohammed, A, (1988), Study on prevalence \& economic significance of bovine Hydatidosis in

[44] Gamo Goffa region, DVM thesis, FVM, AAU, Debre zeit, Ethiopia, pp65

[45] Moidrag, R. \&lan, M.I (1981): Disease of cattle in the tropics, economic \& zoonotic Prevalence. The Hague, Martinus Nijnaft publisher, pp.662

[46] Mitchell, G. B.B. (2001).Treatment and Control of liver fluke in sheep and cattle. Technical Notes November, Sac 2003. West mains roads, Edinburgh.

[47] Mitchel, A. and Yilma, J. (2004): Implication of community based small scale Irrigation in humans and livestock health interaction: acase study in the upper Awash river basin areas. In the partial fulfillment for the attainment of the Degree of Master of Science in biology department, biomedical science, AAU,Ethiopia.

[48] Nebiyou .G (1990) Study of hydatidosis /echinocccosis in cattle slaughtered at Dahir Dar Municipality slaughter house DVMTHESIS, FVM,AAU,DEBREZEIT, ETHIOPIA, pp23

[49] Njau, B.C.kasali, O.B., schaltens, R.G Akalework, N. (1989). The influence of watering Practice on the transmission of fasciola among sheep in Ethiopia highlands. Veterinary research communication 3 (1):67-74

[50] Okewale, E.A Ogundipe, G.A.T. adejinmi, J.O \& Alaniyan, A.O (2000). Clinical Evolution of three chemoprophylactic regimes against ovine helminthiasis in a fasciola Endemin form in Ibadon, Nigeria. Israel Journal of veterinary medicine 56(1):15-28 
The Prevalence of Bovine Fasciolosis and Hydatidosis at Wolita Soddo Municipal Abattoir, Southern Ethiopia.

[51] O’leory, P. (1976): A five year review of human hydatid cyst disease in turkana district, Kenya, east Africa, medical journal, 53:540-544.

[52] Ower, R and Bitakaramine, p.k (1975): Hydatid disease in Uganda. East African medical Journal, 52:700704

[53] Parr,S.I. and Gray, J.S. (2000). A strategic dosing scheme for the control of fasciolosis in Cattle and sheep in lreland . Veterinary Parasitology 88 (3-4): 187-197.

[54] Ramjo, V., Oleaga, A. Casanueva,p.,Hillyer,G.V \& Muro,a. (2001) Vaccination of Sheep against Fasciolahepatica with homologous fatty acid binding proteins Veterinary parasitology 97(1):35-46

[55] Roman Tirunch (1987): Study on economic significance of bovine fasciolosis \& hydatidosis.

[56] Rahamato a, (1992) fasciolosis: Clinical occurrence, Coprological, abattoir \& snail survey In \& around Wolliso. DVM thesis, Addis Ababa university, faculty of Veterinary medicine,deberezeit

[57] Richter, J. Freise, S. Mull, R. and Millan. J.C.(1999). Fasciolosis: sonographic abnormalities of the biliary tract and evolution after treatment with Triclabendazole. Tropical Medicine of International Health 4(11): 774.

[58] Schantz,P.M. (1990): Parasitic zoonosis in perspective international journal of Parasitology, 21(2):165-166

[59] Solusby, E.J.L. (1982) Helminths, arthropds \& protocols of domestic animal $7^{\text {th }}$ Ed, U.S.A Philadeiphia, lee \& Febiger, pp 809.

[60] Slifko,R,Smith,H, V. and Rose, J.B. (2000):- Emerging parasite zoonoses associated with Water and food. Internatonal Journal for Parasitology 30 (12-13): 1379-1393.

[61] Smyth, J.D (1985) introduction to animal parasitology-hodder \& Stoughton, London.

[62] Spithill, T.W. \& Dalton, J.P. (1998): progress in development of Liver fluke caccines. Parasitology today 14(6):224-228.

[63] Tadesse Eguale and Getachew Tilahune (2002): Molluscicidal effects of Endod (Pbytolacca dodecndra) on Fasciola transmitting snails. SINET: Ethiopia Journal of Science 25(2):275-284.

[64] Takele, A (1995): Bovine fasciolosis: prevalence and economic impact at mekele Municipal abattoir, DVM THESIS, FVM, AAU, Debrezeit, Ethiopia,, PP15-17

[65] Tamire, M (2003): Comprehensive mega publishing enterprise, Addis Ababa.

[66] Thrusfield, M, (1995): veterinary epidemiology, $2^{\text {nd }}$ editions. Uk block well science Itd. Pp182 -198.

[67] Thompson, A.D, \& cotton, R.E (1985): Lecture notes on pathology Block well scientific publication.

[68] Torgerson, P., Claxanton,J.(1999). Epidemiology \& Control In: Dalton. J.P. (Ed), Fasciolosis, CAB international publishing wolling ford pp.113-149

[69] Tsegaye Tadesse (1995): Epidemiology of bovine fasciolosis and hydatidosis in debre Birthane regions, DVM thesis, FVM, AAU, Debre zeit, Ethiopia, pp207-208

[70] Urquhart, G.M.Armaur,J.,Duncan, J.L. Dunn, A.M, \& Jennings, F,W, (1996) Veterinary parasitology $2^{\text {nd }}$ ed. Oxford, long man scientific and technical Press, UK,pp.100-109

[71] Urquhart, J.M.,Armour,J.D.,Duncan,J.L., Dunn, A.M.and Jennings, F.W.(1989).Veterinary Parasitology. Low priced ed. English languge book society Longman, Blackwell. Pp.286.

[72] WHO (1995): Control of food born trematode infections. Technical report series No 849 pp.61

[73] WHO (1992) Report of the WHO group meeting on clinical medicine and chemotherapy Alveolar \& cystic echinococcosis. WHO/CDS/VPH/93 pp.118

[74] WHO (2002). Prevention and Control of Scbistosomiasis and soil transmitted Helmintbiasis. Technical Report Series 912,pp.57.

[75] Wolaita Zone rural development department (2003): Basic data of Wolaita zone

[76] Wolaita Soddo finance \& economic main department (2004): Bulletin of socio-economic profile of wolaite zone pp 35

[77] Wllliams, J.F, Adoras, H.L and Terijos, A. (1975): Current prevalence \& Distribution of Hydatidosis with special reference to the Americans.Americans journal of Trop. Med \& Hy. 20:224-233

[78] Wubet, M. (1987): A preliminary study of echinococcosis/ hydatidosis in Harerge region and the efficacy of glinhs latidus seeds against Echinococcus granulosis in pups Infected experimentally with hudatid materials DVM thesis, FVM, AAU, Debrezeit, Ethiopia, pp. 51-52

[79] Wubet, S. (1988), prevalence of cattle hydatidosis and its economic significance in Robe Municipal abattoir. DVM thesis, FVM,AAU, Debre zeit, Ethiopia.

[80] Yilma, J. (1984): a preliminary study of the economic \& public health significance of Echionococcosis in Debre Zeit, Ethiopia, $3^{\text {rd }}$ student scientific journal (55) 
The Prevalence of Bovine Fasciolosis and Hydatidosis at Wolita Soddo Municipal Abattoir, Southern Ethiopia.

[81] Yilma Jobre and Malone, J.B (1998). A grographical information system for east model for strategic control of fasciolosis in Ethiopia veterinary parasitology 78 (2): 103-127

[82] Yilma Jobre (1985) study on ovine fasciolosis and other helmenth parasites at Holota DVM thesis, Faculty of Veterinary Medicine, Addis Ababa University, Debire Zeit, Ethiopia.

[83] Yohanesse, T.(1994): bovine fasciolosis prevalence and economic importance assessment Cattle slaughtered at BahirDar municipal abattoir, DVMTHESIS, FVM, AAU, debrezeit, Ethioia pp 188

[84] Zewdu, B. (1991): prevalence and economic analysis of liver fluke infestation in cattle Slaughtered at Jimma municipal abattoir DVM THESIS, FVM, AAU, debrezeit, Ethiopia. Pp126.

Citation: Firew Lejebo Leka. "The Prevalence of Bovine Fasciolosis and Hydatidosis at Wolita Soddo Municipal Abattoir, Southern Ethiopia.”. International Journal of Research Studies in Biosciences (IJRSB). 7(12), pp. 27-44. DOI: http://dx.doi.org/10.20431/2349-4050.0712004

Copyright: () 2019 Authors this is an open-access article distributed under the terms of the Creative Commons Attribution License, which permits unrestricted use, distribution, and reproduction in any medium, provided the original author and source are credited. 